\title{
La Grèce antique sous le regard du Moyen Âge occidental. Actes du Colloque, Jean Leclant et Michel Zink édd.
}

\section{G. Matteo Roccati}

\section{(2) OpenEdition}

Journals

Edizione digitale

URL: http://journals.openedition.org/studifrancesi/7455

DOI: $10.4000 /$ studifrancesi.7455

ISSN: 2421-5856

\section{Editore}

Rosenberg \& Sellier

\section{Edizione cartacea}

Data di pubblicazione: 1 décembre 2009

Paginazione: 598

ISSN: 0039-2944

\section{Notizia bibliografica digitale}

G. Matteo Roccati, «La Grèce antique sous le regard du Moyen Âge occidental. Actes du Colloque, Jean Leclant et Michel Zink édd.», Studi Francesi [Online], 159 (LIII | III) | 2009, online dal 30 novembre 2015, consultato il 09 janvier 2021. URL: http://journals.openedition.org/studifrancesi/7455 ; DOI: https:// doi.org/10.4000/studifrancesi.7455

Questo documento è stato generato automaticamente il 9 janvier 2021.

\section{cc) (†) $\odot$}

Studi Francesi è distribuita con Licenza Creative Commons Attribuzione - Non commerciale - Non opere derivate 4.0 Internazionale. 


\title{
La Grèce antique sous le regard du Moyen Âge occidental. Actes du Colloque, Jean Leclant et Michel Zink édd.
}

\author{
G. Matteo Roccati
}

\section{NOTIZIA}

La Grèce antique sous le regard du Moyen Âge occidental. Actes du Colloque, Jean LECLANT et Michel zink édd., Paris, Académie des Inscriptions et Belles-Lettres, Diffusion De Boccard, 2005 («Cahiers de la Villa Kérylos», n¹6), pp. 220.

1 Le volume rassemble quatorze communications. On signalera ici seulement celles concernant l'aire française.

2 Jean-Yves TILLIETTE, Graecia mendax, pp. 11-22, donne des précisions sur la manière dont les Occidentaux du haut Moyen Âge se représentaient la Grèce. L'expression de Juvénal qui fournit le titre de la contribution est volontiers reprise, en particulier aux $\mathrm{x}^{\mathrm{e}}-\mathrm{XI}^{\mathrm{e}}$ siècles; en même temps la Grèce est vue comme le berceau du savoir. A travers l'examen de deux œuvres antérieures au XII ${ }^{\mathrm{e}}$ siècle - l'Ecloga Theoduli et la paraphrase des Mythologies de Fulgence par Baudri de Bourgueil - l'article montre l'évolution des attitudes. Dans le premier texte, bien qu'indéniablement elle fascine, la mythologie est vaincue par l'histoire biblique, avec laquelle elle est mise en parallèle; dans le deuxième la fable n'est que le voile sous lequel la vérité se manifeste. Anna Maria BABBI, Le grec de Boèce et les clercs médiévaux: le malentendu, pp. 23-37, en prenant appui sur les commentaires et les traductions médiévales de la Consolatio, retrace la fortune des citations grecques qu'elle contient et qui ont souvent été mal comprises. Birger MUNK OLSEN, La Grèce vue par l'école du XII siècle, pp. 39-49, examine les connaissances relatives à la Grèce antique dans les textes littéraires expliqués dans les cours de grammaire. Jan 
ZIOLKOWSKI, La Grèce antique sous le regard de Gervais de Tilbury, pp. 51-67, confronte la perception attestée par les Otia imperialia avec les témoignages contemporains. Walter BERSCHIN, "Iucundissimae lectiones, quae excitant nobis memoriam eorum, quae deforis sunt». Homère dans le royaume de Frédéric II de Hohenstaufen (1194-1250), pp. 69-78, repère les traces de la présence d'Homère, sans doute «moyen de propagande culturelle», «dans le cercle des savants gravitant autour de l'abbé Nikolaos-Nektarios de Casole près d'Otrante» (p. 78), employés au service de Frédéric II. Danielle JACQUART, Les allusions à la Grèce antique dans les commentaires aux "Problèmes" d'Aristote, pp. 79-94, examine plusieurs exemples (en excluant les références à la mythologie) tirés des commentaires de Pietro d'Abano et d'Evrart de Conty et révélateurs des connaissances de ces auteurs. Michel zINK, Apollonius de Tyr: le monde grec aux sources du roman français, pp. 131-145, reprend de manière synthétique l'ensemble des données concernant ce texte, étranger au monde médiéval, mais profondément assimilé par lui. Jacqueline CERQUIGLINI-TOULET, L'imaginaire de la langue grecque au Moyen Âge, pp. 147-157, relève les références à la langue et à l'alphabet grecs. Isabelle HEULLANT-DONAT, La Grèce antique au miroir de l'histoire universelle: l'exemple de la "Tabula super Speculum historiale fratris Vincentii" de Jean Hautfuney (v. 1320), pp. 159-174, examine la manière dont l'histoire grecque est présentée au sein de l'histoire universelle en se servant notamment des entrées de la table alphabétique établie pour le Speculum historiale de Vincent de Beauvais par Jean Hautfuney, «un clerc mal connu, procureur du roi de France à la curie sous le pontificat de Jean XXII qui finit ses jours comme évêque d'Avranches (1330-1358)» (p. 165). Estelle DOUDET, Le miroir de Jason: la Grèce ambiguë des écrivains bourguignons au $\mathrm{XV}^{e}$ siècle, $\mathrm{pp}$. 175-193, étudie le sens de la référence à la Grèce dans la propagande bourguignonne. 